\title{
Judgment of Liability in Driverless Car Traffic Accidents
}

\author{
Qing Sun \\ China Jiliang University \\ Hangzhou, China
}

\begin{abstract}
With the rapid development of artificial intelligence technology, driverless technology emerges at the historic moment, resulting in endless legal issues. Currently, the legal provisions and product standards of driverless cars in China are not clear, which leads to the difficulty in determining accident liability. From the legal subject qualification dispute of artificial intelligence, this paper analyzes the nature of the liability for tort in driverless car traffic accidents. And within the existing law framework of tort liability in China, it demonstrates the accident responsibility determination under different scenarios and seeks proper ways to solve the driverless car accident responsibility so as to booster driverless industry development from the legal level.
\end{abstract}

Keywords-artificial intelligence; driverless car; product responsibility

\section{INTRODUCTION}

In recent years, "artificial intelligence" technology has made rapid progress, and legal issues based on artificial intelligence have become a hot topic in academia. As a key field for the application of artificial intelligence technology, the world's leading network technology companies are developing relevant products and putting them into trial use. Experts predict that there will be about $1 \%$ of driverless cars in China in 2025. According to the existing car ownership and growth rate, there will be 300,000 to 500,000 selfdriving cars on public roads [1]. However, a number of driverless car accidents around the world are also thoughtprovoking. On March 28, 2018, an Uber tester driving a driverless car killed a female pedestrian in Arizona, US [2], which was the world's first fatal driverless car accident. In the Uber case, the driverless car was made by Volvo. Uber modified its system to include driverless sensor chips, and assigned employees to conduct road tests. Finally, the artificial intelligence system independently controls the driving of the car and causes death. These seemingly simple traffic accidents involve automobile manufacturers, system developers, drivers and artificial intelligence itself. The involvement of multiple factors makes the analysis of accident liability of driverless cars extremely complicated.

Xie Fei. "China will complete the formulation of relevant standards for autonomous driving in 2018". http://auto.qq.com/a/20160606/038902.htm. (in Chinese)

News, Uber self-driving car fatality, New Scientist, Vol.237, 2018, pp.7-7. 1
Although the case is eventually settled, the incidence of such accidents is bound to increase dramatically with the mass production of driverless cars. In the future, China's driverless car accident liability disputes will face two urgent legal problems. First, the subject of tort liability and the distribution of liability are not clear. Second, the quality and safety standards as the basis of product liability identification are unclear. In this regard, it is still necessary to carry out systematic analysis and research around the issue.

\section{SUBJECT OF RESPONSIBILITY: REFLECTION ON THE LEGAL PERSONALITY OF ARTIFICIAL INTELLIGENCE}

The responsibility of driverless car accidents causing death is generally considered to be the same as that of ordinary traffic accidents. But according to the regulation in China's "Road Traffic Safety Law", the accident liability of motor vehicle traffic accident should be judged according to the fault of the motor vehicle driver. It can be seen that the premise of determining traffic accident liability is that there is a motor vehicle driver. In other words, only when someone is driving can it be identified as a motor vehicle and be handled as liability for motor vehicle traffic accidents according to the "Road Traffic Safety Law".

In the Uber case, there is a clear record that the tester did not touch the driving system. In the case of fully automatic driving of the artificial intelligence system, it is necessary to determine whether there is a "driver" in the first place if the liability for traffic accident of the motor vehicle is to be determined. Therefore, in the case of driverless car accident liability, if there is no human factor involved, the first consideration is whether the artificial intelligence system is capable of assuming responsibility, that is, the subject qualification of artificial intelligence. The development of artificial intelligence technology has a great impact on existing laws. Whether the artificial intelligence equipment has legal personality or not and whether it can become the qualified legal subject is the most prominent core legal issue of artificial intelligence at present [3].

Fan Zhongxin. Conservative Thinking on the Legal Confusion of Artificial Intelligence. Exploration and Free Views, No.9, 2018, page 80 (in Chinese) 


\section{A. Debate on the Legal Status of Artificial Intelligence}

It is generally believed that the principle of artificial intelligence technology is based on human's intelligent behavior in natural language understanding and learning, as well as reasoning problem solving and other aspects. The system designed by artificial intelligence should have similar characteristics, that is, the ability to think like human beings [4]. The most important feature of artificial intelligence is that it has independent consciousness, and is not subject to the will of people [5]. However, it is clear that the current human technology is not able to make real AI, but "a technology about simulating, extending and augmenting human intelligence" [6]. Some scholars believe that from the perspective of current technology, it is more practical to discuss the legal personality of artificial intelligence from the perspective of AI.

According to the principle of the traditional civil law, the legal subject is the existence of the person or other kind of person who enjoys the right, performs the obligation or assumes the responsibility in the legal relationship, and the legal subject in a real sense must be able to be responsible for its own behavior. Without the legal responsibility, the provisions of the legal subject are meaningless [7]. This also means that if the artificial intelligence is deemed to have the qualification of legal subject, it should be able to assume legal responsibility independently of the designer and producer. In this regard, some scholars put forward that it must be regarded as a special subhuman existence in the future and given legal personality [8]. But the mainstream view is basically negative. Some scholars believe that artificial intelligence does not have the ethical attributes of biological human beings, so it cannot become the legal subject with the legal status of biological human beings [9]. There are also some views that artificial intelligence is neither a biological person, nor a legal person of biological collection, and does not have the qualification of legal subject [10]. The author holds a conservative attitude towards this. At least from the development status of driverless car technology, artificial intelligence does not have the possibility and necessity of independent legal personality.

4 See Bao Junpeng, Zhang Xuanping. Introduction to Artificial Intelligence, China Machine Press, 2015, page 2. (in Chinese)

John Markoff. A Brief History of Artificial Intelligence. Guo Xue Trans. Zhejiang People's Publishing House, 2017, page 328. (in Chinese)

6 Wu Handong. Challenges of Artificial Intelligence to the Legal Protection of Intellectual Property Rights. China Law Review. Issue 2, 2018, page 2. (in Chinese)

Wang Yong. Theoretical Construction of Legal Subject in the Era of Artificial Intelligence - Starting from Intelligent Robot. Journal of Socialist Theory Guide, 2nd issue, 2018, page 64. (in Chinese)

Yang Qingwang, Zhang Lei. On the Artificial Legal Personality of Artificial Intelligence. Journal of Hunan University of Science and Technology (Social Science Edition), No.6, 2018, page 92. (in Chinese)

Zhu Chengbin, Li Yong. Artificial Intelligence, as a Legal Fiction, Cannot Possess Biological Human Exclusivity. Journal of Shanghai Jiao Tong University (Social Science)". https://doi.org/10.13806/j.cnki.issn1008-7095.2018.010. (in Chinese)

10 Wu Handong. Institutional Arrangement and Legal Regulation in the Era of Artificial Intelligence. Science of Law (Journal of Northwest University of Political Science \& Law), No.5, 2017, p. 131. (in Chinese)
It can only be regarded as an extension of human body and a tool for human service, so it can be regarded as an object in the civil legal relationship.

\section{B. Denial of Subject Qualification of Artificial Intelligence}

The essence of artificial intelligence equipment is that it is designed, developed and manufactured according to the instructions of human beings through various high-tech means to realize functions similar to human brain. Therefore, it has the attributes of objects rather than human beings. Although it has certain autonomous behaviors, it is still an object [11]. And the AI devices can only be designed to obey the law but can't really understand the law [12]. It is also unable to bear the tort liability caused by the act independently, and the damages caused by it will eventually be borne by other liability subjects because it has no independent property. At present, the development level of artificial intelligence in the world is still in the stage of weak artificial intelligence. Moreover, only in a specific field does it show human-like professionalism. It does not yet possess the free will of a legal natural person and cannot fully exercise its obligations and enjoy rights. Therefore, artificial intelligence equipment can not only be given legal subject qualification according to its professionalism and advancement just in some aspects.

The traditional theory of civil law holds that anything other than human beings without spirit and intention belongs to the category of objects, that is, the object of rights. In addition, there are no provisions on the damage caused by artificial intelligence equipment and no recognition of its legal personality. Therefore, at present, artificial intelligence can only be regarded as the object of legal relations, not enough to obtain independent subject status. On the premise that the law cannot recognize it as a new subject, artificial intelligence can only be excluded from the legal subject. However, in the future, artificial intelligence technologies will definitely develop further. They may be able to determine their actions through their independent will and have the characteristics of legal subjects. At that time, perhaps artificial intelligence can be considered giving the qualification of legal subjects and constructing the legal subject framework of its equipment.

\section{PRODUCT DEFECT: THE CORE ELEMENTS OF ACCIDENT LIABILITY DETERMINATION OF DRIVERLESS CARS}

Since the legal subject qualification of artificial intelligence is denied, driverless car accidents can only fall into the category of product liability. However, there are significant differences between artificial intelligence products and ordinary products. Within the framework of the traditional product liability system, it needs further demonstration to determine whether the liability of driverless cars in accidents can be solved.

11 Xu Huimeng, Wang Feifei. Identification of Tort Liability for Artificial Intelligence. Journal of Chang'an University (Social Science Edition), No.4, 2018, page 59. (in Chinese)

12 Wu Xiyu. How Should Law Think About Artificial Intelligence? Zhejiang Social Science, 2018, No. 6, page 67. (in Chinese) 


\section{A. The Field Extension of Traditional Product Liability}

According to the current law, if a motor vehicle causes a traffic accident due to its own quality, the accident can be classified as product defect liability. And according to the regulations in article 41 of the "Tort Liability Law" and article 43 of "Product Quality Law" of China, the producer or seller of the product shall bear the unreal joint-liability according to the principle of no-fault liability, that is, the victim can claim compensation from both the producer and the seller of the product [13]. Similarly, if a driverless car is involved in an accident due to a problem with the car's own parts, the same rule applies and the car's seller or manufacturer is not really jointly and severally liable.

In the traditional concept, the automobile as a product is only a tool of human control, and there is no need to discuss its personality attributes. But under the artificial intelligence technology, the driverless car has the precise artificial property, which brings the challenge to its applicable product liability. Although artificial intelligence products have a certain degree of autonomy, they are derived from the program design of engineers and manufacturers, and their intelligence is limited to specific application scenarios. The product liability mode can avoid the discussion on the qualification of the right as principal of artificial intelligence, and its feasibility can be proved from the opposite perspective [14]. Therefore, it should be a product liability problem when a driverless car is involved in an accident and the legal liability needs to be analyzed, and the manufacturer's product liability can be investigated on the grounds of product defects [15]. In this way, driverless car accidents can be completely solved under the original product liability framework.

\section{B. Product Defect Determination of the Driverless Car}

According to the relevant provisions of the "Tort Liability Law" of China, when there are defects in artificial intelligence products, the producer shall assume the responsibility, and its constituent elements include product defects, damage and causal relationship. According to the "Product Quality Law", product defects can be classified into three types: design defects, manufacturing defects and warning defects. For the first two, it would be easier to prove that a driverless car has a manufacturing defect in its own mechanical equipment; but if its internal artificial intelligence system design is defective, because of its advanced technology and unpredictability, and according to the regulation of existing civil evidence rules in China, the injured party has the burden of proof to prove the defect of the product, but it is difficult for the injured party to proof that the artificial intelligence system internal algorithm or

13 Zhao Xianfei. Study on the Legal Liability of Unmanned Vehicles in Traffic Accidents. Journal of Bengbu University Feb. 2018 Vol. 7, No.1, page 91. (in Chinese)

14 Zhang Jianwen, Jia Zhangfan. Liability Analysis and Rule Response to the Damage Caused by Driverless Cars. Journal of Chongqing University of Posts and Telecommunications (Social Science Edition), No.4, 2018, page 34. (in Chinese)

15 Liu Xiaochun, Da Yachong. A Review of the Legal Personality of Intelligent Robots. Forward Position, 2018, No.3, page 85. (in Chinese) programming is flawed, harder to further prove the existence of the algorithm will have "unreasonable danger to the safety of person or property". Even if there is a traffic accident, because the artificial intelligence has a high degree of autonomy and learning ability, and its acquired learning ability is beyond the control of the original manufacturer, it is difficult to understand and explain the learning, judgment and decision-making process conducted by the artificial intelligence according to the algorithm, so it is hard to pin the blame on producers. It can be seen that the identification of defects in driverless cars is extremely complicated. Therefore, while stepping up the formulation of legal standards, general standards for the comprehensive judgment of unreasonable dangers should also be made in light of the description, use, and intelligence level and circulation time of driverless cars [16].

Of course, according to the exemption clause stipulated in article 41 of the "product quality law", the exemption condition for driverless car accidents is that the science and technology then cannot find its defects when the driverless car is put into circulation. Since the artificial intelligence computer system in the driverless car can analyze the road traffic information in real time, and the problem of system responsibility is a kind of high probability event that ordinary people can expect, and defects of the system itself are an exemption, the author believes that there is no exemption from liability for product defect accidents in driverless cars.

\section{RESPONSIBILITY BEARING: THE BOUNDARY OF LIABILITY FOR DRIVERLESS CAR ACCIDENTS IN DIFFERENT SCENARIOS}

As mentioned above, there are different scenarios of driverless car accidents, and it is necessary to distinguish the causes of different accidents to determine tort liability, instead of simply solidifying the types of tort liability. Based on the artificial intelligence characteristics of unmanned driving, specific responsibilities can be divided as follows from different perspectives of traffic accident causes.

\section{A. Responsibility of Users of Driverless Cars}

First of all, since driverless cars have the attributes of ordinary motor vehicles, in the case of operating by a driver, there should be no objection to the investigation of the responsibility of the driver in accordance with the "Road Traffic Safety Law". By extension, the user of the equipment is the direct operator of artificial intelligence products. If the user does not use or operate artificial intelligence products correctly, damage may be caused. In this circumstance, the artificial intelligence product itself does not have any technical problems, and the product has no defects. It is only because the user did not use it strictly according to the instructions in the process of use that the accident was caused. At this time, attention should be paid to the analysis of whether the car user is at fault, such as whether he or she

16 Yang Fangling. Study on Legal Issues of Infringement of Artificial Intelligence Products. Journal of Anhui Vocational College of Electronics \& Information Technology. No.5, 2018, page 89. (in Chinese) 
has a full understanding of the performance of the product and whether there are operating errors. Some artificial intelligence products may require users to check regularly or even return to the factory for maintenance, but the user did not comply with the requirements, or do not follow the manual requirements correctly use, which led to the danger, in which case the user has fault. As a new type of artificial intelligence equipment, driverless car is very different from ordinary vehicle. Therefore, the existing laws cannot comply with the development of driverless cars. According to the general knowledge of the public, if a traffic accident occurs to an ordinary motor vehicle, the responsible person should be the owner or user of the vehicle. However, unlike ordinary motor vehicles, driverless cars can only control the vehicle to complete corresponding actions after receiving instructions. Therefore, users of driverless cars need to take responsibility, unless the user can prove that the accident was caused by a problem with the driverless car itself, in which case the car's manufacturer is liable.

\section{B. Responsibility of the Software Developer of the Driverless Cars}

When an accident happens to a driverless car, it is likely to be caused by the fault of the system itself, in which circumstance the driverless car cannot accurately judge the surrounding complex environment in the process of driving, thus resulting in personal safety and property damage. So in this case, it makes sense to let suppliers of intelligent systems for driverless cars bear the main responsibility for the accident [17]. Research and development of artificial intelligence products requires special knowledge and technical background, and the design and development is the first link. The design thinking and program writing of software developers will affect the production and use of products and other related processes, and directly affect the safety of product users. Therefore, if there is a mistake in the research and development stage, it will have a significant impact. Different from traditional vehicles, the system developer, as an important support for the construction of the whole driverless vehicle operation system, determines the safety, stability and reliability of the vehicle operation to a large extent [18]. Therefore, if an accident of a driverless car causes damage and the cause of the accident is identified as being caused by a mistake in the research and development of the artificial intelligence equipment, then the research and development personnel of the equipment need to take responsibility for the accident.

\section{Responsibility of Product Producer of the Driverless Cars}

Besides the research and development of artificial intelligence equipment, the production process is also

17 Chen Jiali. The Legal Idea of Liability in Driverless Car Traffic Accidents. Journal of Xiang Yang Vocational and Technical University, No.2, 2018, page 119. (in Chinese)

18 Yuan Yuan. Legal Considerations on Road Traffic Accidents of Driverless Cars in China. Journal of Chongqing University of Posts and Telecommunications (Social Science Edition), No.4, 2018, page 42. (in Chinese) important. The manufacturer of artificial intelligence products makes quantitative production of the products designed by the designer. In this process, whether the technical specifications used by the manufacturer meet the standards will directly affect the quality of the products. As the subject of product liability, the producer bears the liability without fault, which has been widely recognized by all countries. When driverless cars have a traffic accident, it is most likely because of the quality of the driverless cars themselves. In such cases, manufacturers of driverless cars would be held liable if they could not prove that there were no "unreasonably dangerous" in their vehicles and that they had done all they could to take care. In addition, the relevant provisions of product liability in China's "Product Quality Law" can be applied to request the manufacturer to assume ultimate responsibility for personal damage and property damage caused by accidents resulting from design defects or quality defects of driverless cars. If a manufacturer "knowingly" produces a driverless car with defects that result in the death of a victim due to other injury consequence, regulation under article 47 of the "Tort Liability Law" may be considered. At the same time, the manufacturer shall have the obligation to follow up the condition of its products after the sales of driverless cars. When defects are found in the products, the manufacturer shall take timely warning, recall and other remedial measures, otherwise the manufacturer shall assume corresponding responsibilities [19].

\section{CONCLUSION}

With the progress of science and technology and the rapid development of artificial intelligence technology, the emergence of driverless cars has broken the status quo of the traditional automobile industry and road traffic safety, and many unexpected new situations and new legal issues have emerged. Currently, the focus of unmanned driving in China is still in the stage of encouraging technology research and development and industrial development, and there is still a lack of overall understanding and active deployment of the social impact of artificial intelligence technology. At present, many countries around the world have started to actively introduce the product standards of driverless cars, make and revise relevant laws and regulations. China should also pay attention to driverless cars from the legal level, focus on the analysis of the liability subject and liability identification of driverless cars accidents, and according to China's actual situation, learn from relevant foreign legislative experience, formulate the laws and regulations that best suit China's national conditions, so that China's driverless cars industry has a better development.

19 Yuan Yuan. Legal Considerations on Road Traffic Accidents of Driverless Cars in China. Journal of Chongqing University of Posts and Telecommunications (Social Science Edition), No.4, 2018, page 42. (in Chinese) 


\section{REFERENCES}

[1] Xie Fei. "China will complete the formulation of relevant standards for autonomous driving in 2018". http://auto.qq.com/a/20160606/038902.htm. (in Chinese)

[2] News, Uber self-driving car fatality, New Scientist, Vol.237, 2018, pp.7-7. 1

[3] Fan Zhongxin. Conservative Thinking on the Legal Confusion of Artificial Intelligence. Exploration and Free Views, No.9, 2018, page 80. (in Chinese)

[4] Bao Junpeng, Zhang Xuanping. Introduction to Artificial Intelligence, China Machine Press, 2015, page 2. (in Chinese)

[5] John Markoff. A Brief History of Artificial Intelligence. Guo Xue Trans. Zhejiang People's Publishing House, 2017, page 328. (in Chinese)

[6] Wu Handong. Challenges of Artificial Intelligence to the Legal Protection of Intellectual Property Rights. China Law Review. Issue 2, 2018, page 2. (in Chinese)

[7] Wang Yong. Theoretical Construction of Legal Subject in the Era of Artificial Intelligence - Starting from Intelligent Robot. Journal of Socialist Theory Guide, 2nd issue, 2018, page 64. (in Chinese)

[8] Yang Qingwang, Zhang Lei. On the Artificial Legal Personality of Artificial Intelligence. Journal of Hunan University of Science and Technology (Social Science Edition), No.6, 2018, page 92. (in Chinese)

[9] Zhu Chengbin, Li Yong. Artificial Intelligence, as a Legal Fiction, Cannot Possess Biological Human Exclusivity. Journal of Shanghai Jiao Tong University (Social Science)". https://doi.org/10.13806/j.cnki.issn1008-7095.2018.010. (in Chinese)

[10] Wu Handong. Institutional Arrangement and Legal Regulation in the Era of Artificial Intelligence. Science of Law (Journal of Northwest University of Political Science \& Law), No.5, 2017, p. 131. (in Chinese)

[11] Xu Huimeng, Wang Feifei. Identification of Tort Liability for Artificial Intelligence. Journal of Chang'an University (Social Science Edition), No.4, 2018, page 59. (in Chinese)

[12] Wu Xiyu. How Should Law Think About Artificial Intelligence? Zhejiang Social Science, 2018, No. 6, page 67. (in Chinese)

[13] Zhao Xianfei. Study on the Legal Liability of Unmanned Vehicles in Traffic Accidents. Journal of Bengbu University Feb. 2018 Vol. 7, No.1, page 91. (in Chinese)

[14] Zhang Jianwen, Jia Zhangfan. Liability Analysis and Rule Response to the Damage Caused by Driverless Cars. Journal of Chongqing University of Posts and Telecommunications (Social Science Edition), No.4, 2018, page 34. (in Chinese)

[15] Liu Xiaochun, Da Yachong. A Review of the Legal Personality of Intelligent Robots. Forward Position, 2018, No.3, page 85. (in Chinese)

[16] Yang Fangling. Study on Legal Issues of Infringement of Artificial Intelligence Products. Journal of Anhui Vocational College of Electronics \& Information Technology. No.5, 2018, page 89. (in Chinese)

[17] Chen Jiali. The Legal Idea of Liability in Driverless Car Traffic Accidents. Journal of Xiang Yang Vocational and Technical University, No.2, 2018, page 119. (in Chinese)

[18] Yuan Yuan. Legal Considerations on Road Traffic Accidents of Driverless Cars in China. Journal of Chongqing University of Posts and Telecommunications (Social Science Edition), No.4, 2018, page 42. (in Chinese)

[19] Yuan Yuan. Legal Considerations on Road Traffic Accidents of Driverless Cars in China. Journal of Chongqing University of Posts and Telecommunications (Social Science Edition), No.4, 2018, page 42. (in Chinese) 